\title{
Contemporaneous financial intermediation
}

\section{How DLT changes the cross-border payment landscape}

\author{
Markus Merz ${ }^{1}$ \\ Received: 18 December 2020 / Accepted: 19 February 2021 / Published online: 8 March 2021 \\ (c) The Author(s) 2021
}

\begin{abstract}
Digital innovations in banking and payments recently have garnered a great deal of attention. Specifically, distributed ledger technology (DLT) has the potential to fundamentally change the roles and responsibilities of stakeholders in the financial sector. DLT is a novel and fast-evolving approach to record and share data, e.g., payment transactions, among members of a decentralized network. Using transaction cost theory, the paper examines how DLT will change the cross-border payment infrastructure. DLT can reduce the overall transaction costs potentially resulting in the disappearance of correspondent banks.
\end{abstract}

Keywords Distributed ledger technology $\cdot$ Cross-border payments $\cdot$ Transaction costs $\cdot$ Correspondent banking $\cdot$ Ripple $\cdot$ Intermediation

JEL classification $\mathrm{E} 42 \cdot \mathrm{G} 21 \cdot \mathrm{O} 30 \cdot \mathrm{P} 51$

\section{Introduction}

Banks have long been rationalized by their seemingly essential role as financial intermediaries in an economy. Traditionally, banks are thought to intermediate between non-banks, such as households and firms (Diamond and Dybvig 1983; Diamond 1984). However, less regarded, but equally important banks also provide payment services. ${ }^{1}$

Cash is ill-suited for large payments, especially over a long distance. In this context, banks allow customers to transfer money in a safe and secure manner. Due to

\footnotetext{
1 Strictly speaking, banks started as providers of payment services and then extended into financial intermediation services (Kohn 1999).

Markus Merz

markus.merz@uni-tuebingen.de

1 Department of Banking, University of Tuebingen, Tübingen, Germany
} 
the globalization of both business and private transactions, and growing financial integration, transferring money across borders has become a pervasive issue.

For centuries, banks have dominantly carried out cross-border payments via correspondents, i.e., interbank intermediaries that complete transactions on behalf of banks in areas where they are not physically present (Society for Worldwide Interbank Financial Telecommunication 2016; Calomiris and Carlson 2017; Committee on Payments and Market Infrastructures 2018). Today, however, this model faces significant challenges. For example, banks must compete with faster, cheaper, and more transparent (online) payment service providers (e.g., PayPal, TransferWise, WeChat Pay, Alipay, Amazon Pay, etc.). Many of these new intermediaries carry out transactions within their own ecosystem, instantly shifting money from one account to another. Surprisingly, according to Denecker et al. (2016), more than $95 \%$ of business-to-business and approximately $60 \%$ of consumer-to-consumer cross-border transactions are still processed by banks. ${ }^{2}$ The authors cite proven security of banks for both money and data as the dominant reason.

Despite the longstanding dominance of banks, the competition remains fierce as cross-border payments are extremely profitable. About $\$ 136$ trillion flow across borders annually (Bruno et al. 2019). Although this is only one-sixth of all global payments, it generates about $30 \%$ of the revenues that processors collect, totaling more than $\$ 230$ billion per annum (Bruno et al. 2019). To insure their control, banks are continually working on improvements. For example, the Society for Worldwide Interbank Financial Telecommunication's global payments innovation (SWIFT gpi) improves the speed, transparency, and traceability of cross-border payments, but still relies on the correspondent banking system. More recently, however, banks have started to explore an innovation that could profoundly transform the cross-border payment infrastructure: Distributed Ledger Technology. DLT is decentralized and the network participants hold identical copies of a shared database that is updated algorithmically. The usage of DLT eliminates the need for third parties, i.e., correspondent banks, to manage and reconcile individual bank accounts. Although there are still significant legal, regulatory, and operational barriers to the global implementation of such a system, DLT already has the potential to replace correspondent banks and dominate cross-border payments. In the presented research, the unconventional but highly pertinent transaction cost model of Breuer (1993) is introduced and adapted to predict how DLT will increase the efficiency and resiliency of crossborder payments. The paper begins by explaining the role of correspondent banks as interbank intermediaries. Subsequently, the potential impact of DLT on the presented market structure is analyzed. It is shown that the use of DLT could reduce the economy-wide transaction costs making correspondent banks superfluous.

The presented findings contribute to the nascent literature on technological disruption in the banking sector (see, e.g., Swan (2015), Vives (2019), Boot et al. (2021)) by explicitly examining how DLT changes the cross-border payment market. DLT is highly discussed in the field of cross-border payments (Bank of Canada,

\footnotetext{
2 More recently, Rice et al. (2020) reinforce this finding stating that the overwhelming majority of crossborder transactions are processed by banks.
} 
Bank of England, and Monetary Authority of Singapore 2018; Newman et al. 2018) and has even been implemented (Rapoport et al. 2014). With the exception of Mills et al. (2016), He et al. (2017), and Casu and Wandhöfer (2018), academic reports, however, are limited and incomplete. Mills et al. (2016), for example, only broached the topic in their broader work on payment, clearing, and settlement. He et al. (2017) and Casu and Wandhöfer (2018) provide a more comprehensive analysis of the implementation of DLT in cross-border payments. ${ }^{3}$ Casu and Wandhöfer (2018) qualitatively evaluated the potential of DLT and several other network models by surveying members of the industry. The findings presented here complement this earlier work by explicitly examining potential effects on the costs and the design of payment infrastructure. In their work, He et al. (2017) offer a conceptual framework to assess the impact of DLT on the cross-border payment market. Although they claim that through its technical characteristics, DLT has the potential to reduce transaction costs, they do not quantify the effect. There are, however, substantial costs associated with migrating from existing longstanding IT systems, operational arrangements, and institutional frameworks to a DLT-based payment infrastructure (Natarajan et al. 2017). A tool to accurately estimate potential costs savings is therefore highly desirable for bank managers, regulators, and central bankers. Here, a theoretical framework is provided that allows a detailed estimation of the transaction costs in the current correspondent banking system and in a DLT-based system. Additionally, the systematic and thorough characterization of DLT will help provide clarity to the often disorganized existing literature on the nascent technology (Perdana et al. 2020).

Finally, the presented work is related to the literature on optimal intermediation structures. Craig and von Peter (2014) and Calomiris and Carlson (2017) provide evidence that banks themselves rely on another layer of intermediation for a variety of functions. The presented theoretical framework shows the cost benefit of interbank intermediation using the example of correspondent banks and how a DLT system like RippleNet can not only transform existing cost structures, but also the interbank market. Since the stability of the financial system greatly depends on the interbank network topology (Hüser 2016), the insights here also have important implications for future regulation.

\footnotetext{
3 The direct use of central bank digital currencies for cross-border transactions is also examined in the literature (Koning 2016; Raskin and Yermack 2018; Auer and Boehme 2020). Although this idea seems promising, economists have several reservations, e.g., privacy issues, or the limited operational capacity of central banks to deal with individuals (see, e.g., Kahn et al. (2019) for an insightful discussion on this topic). Additionally, Boar et al. (2020) found that the overwhelming majority of central banks see themselves as unlikely to issue any type of such a currency in the foreseeable future. Other studies examine the specific example of Bitcoin (Böhme et al. 2015; Narayanan et al. 2016) and its use as virtual currency (Rysman and Schuh 2017). Scalability and transaction speed, however, are limited in the Bitcoin system (Natarajan et al. 2017).
} 


\section{The foundation of interbank intermediaries}

\subsection{The concept of correspondent banking}

The ability to safely and securely transfer money both within and across borders is indispensable for a functioning economy. Until the middle ages, banks were municipally chartered institutions and could offer payments services only within their home city (Quinn 2008). As a result, funds had to be physically transferred. A process that was often plagued by theft, confiscation, and loss at sea. As long-distance trade increased, better suited transaction means were needed. The bill of exchange became available as a new payment instrument during the 13th century. Bills of exchange are written instructions from a drawer to a drawee, a correspondent in a different city, to give funds to a payee. Initially, correspondents were often merchants, with time banks were used more frequently due to their ubiquitous network and ample liquidity. Starting in the 17th century, ongoing improvements in interbank relationships and the emergence of new payment instruments simplified inter-regional and cross-border payments (Quinn 1997, 2008). By the end of the 19th century, certain banks began to specialize in mediation of long-distance transactions, i.e., correspondent banks (see, e.g., Calomiris and Carlson (2017) for an overview of the U.S. corresponding banking network at that time). Today, most other banks rely on these correspondent banks to complete transactions on their behalf in areas where they are not physically present (Society for Worldwide Interbank Financial Telecommunication 2016; Rice et al. 2020).

The intermediary banking services are controlled by a few large correspondents, i.e., the market is typical for an oligopoly. According to the European Central Bank, in 2016, there were 401 correspondent banks involved in the Euro business that served 9,754 customer banks (European Central Bank 2016). Based on data from the Committee on Payments and Market Infrastructures (2019), it is estimated that the number of correspondent banks had decreased to about 361 by the end of 2018 . Although the exact number of correspondent banks globally is publicly unknown (Committee on Payments and Market Infrastructures 2016, 2019), the total number is declining, i.e., the market is increasingly concentrated.

In the succeeding sections, for simplification, correspondent banks will only be referred to as correspondents. The modern correspondent banking model consists of an international network of financial institutions, where the sender and the beneficiary bank employ an intermediary (the correspondent) to sort and process crossborder payments. The sender and the beneficiary bank hold Nostro (Italian: ours, which refers to 'our account with you') account with the correspondent. Due to the absence of a direct account relationship, the correspondent provides Loro (Italian: theirs, which refers to 'their account with them') accounts on behalf of the sender and the beneficiary bank. ${ }^{4}$ The financial information, to settle transactions by crediting and debiting the accounts, is exchanged via the SWIFT's network (Grant 1986;

\footnotetext{
${ }^{4}$ Note that this is the most simple structure. In principle, there could be additional correspondents involved on the sending and receiving sides.
} 


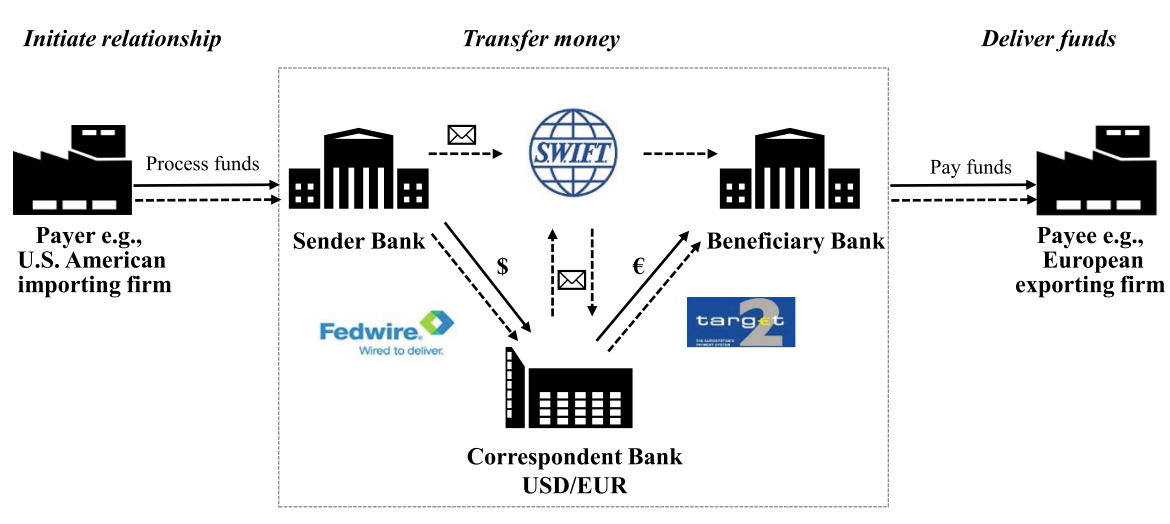

$\longrightarrow$ Payment flow ------- Data flow

Fig. 1 Correspondent banking system today

Society for Worldwide Interbank Financial Telecommunication 2016). The payment instruction flows through an entry posting system, which creates a debit to the sender's account and either a credit to the beneficiary's account if this is held with the same correspondent or a posting to the payment system queue for settlement over the national/regional payment system. The payment flows from one bank to another through a central bank clearing system. There are two main types of settlement systems: real-time gross settlement (RTGS) and deferred net settlement (DNS). While in a DNS system (such as the Clearing House Interbank Payments System, CHIPS in the U.S.), all unsettled transactions are gathered and processed in bulk, RTGS systems (such as Fedwire in the U.S. or the Trans-European Automated Real-time Gross settlement Express Transfer system, TARGET2 in Europe) process money in real time.

To illustrate the payment processing via a correspondent, consider the following example. An U.S. American importer instructs its regional bank, i.e., the sender bank, to make a payment to a European firm (compare Fig. 1). It is important to note that the payment instructions are exchanged separately from the "physical" flow of payments between the corresponding parties. The European firm has an account at Deutsche Bank with which the regional bank, e.g., the Bank of Colorado, has no banking relationship. However, both the Bank of Colorado and Deutsche Bank have a correspondent banking relationship with the Bank of America, i.e., they both hold Nostro accounts at the Bank of America. Like the Bank of Colorado, the Bank of America has an account at the Fed and thus receives the funds through the national payment system, e.g., Fedwire. The Bank of America provides Loro accounts for their bank clients that they can make and receive USD and foreign currency payments. Upon receiving the USD in its Federal Reserve account, Bank of America does a book-entry transfer to credit Deutsche Bank's USD Nostro account for the amount of the payment. Bank of America then converts the USD to Euro, so it can send the payment to the German supplier's account at Deutsche Bank. 
Correspondents are used, because accounts at the central bank governing the particular currency are required for a transfer. In this example, Deutsche Bank does not have an account at the Fed. As a result, Bank of America cannot "physically" move the USD to Deutsche Bank. Assuming the supplier would like to either withdraw the funds or use them to make a Euro payment, Bank of America must first do a separate foreign exchange transaction to convert the funds to Euro. To do this, the Bank of America will debit Deutsche Bank's USD Nostro account and then credit Deutsche Bank's Euro Nostro account for the Euro equivalent. Bank of America then sends the Euro amount via the European Central Bank settlement system, TARGET2, to Deutsche Bank, since Deutsche Bank has a TARGET2 account. Once Deutsche Bank has the funds, it can credit the supplier's account, and the supplier can make a Euro payment or withdrawal.

In terms of costs of cross-border payments, each bank in the payment process charges payment processing fees (Casu and Wandhöfer 2018). ${ }^{5}$ Each bank also individually conducts know-your-customer, anti-money laundering, and counter-terrorist-financing checks. In addition, network and liquidity costs are involved in maintaining correspondent relationships. Costs arise for each bank that is involved in the process of funding interbank accounts and managing exposures.

\subsection{The theory of interbank intermediation}

To better understand the formation of interbank intermediaries in cross-border payments, the model of Breuer (1993) is introduced and adapted. For this model crossborder transactions are defined as the transfer of a fixed amount of money from one currency zone into another. Two banking systems with $n$ domestic banks $(D)$ and $m$ foreign banks $(F)$ are considered, the bilateral network and the corresponding banking system. In the bilateral network (compare Fig. 2), on behalf of their clients, each domestic bank must handle the sorting and processing of payments directly with its foreign counterpart. In this system, there are $m * n$ possible interbank transactions.

In contrast, the presence of $j$ intermediary correspondents $(B)$ results in $n * j+m$ transactions (compare Fig. 3). In this case, all institutions forward payment instructions to correspondents that operate solely in a specific region (e.g., in one country, state or jurisdiction, etc.), to sort and process. In this system, the number of interbank transactions is reduced if the number of correspondents is sufficiently low, i.e., $j \leq \frac{m(n-1)}{n}$ holds true. In other words, as long as every correspondent $j$ serves more than two foreign banks $m$, the correspondent system results in a lower number of interbank transactions. Note that the modeled structure implies that each domestic bank has access to all service-providing correspondents. As only "a few key players [account] for the majority of loro account turnover" (Committee on Payments and Market Infrastructures 2016, p. 15), this seems to be a reasonable assumption for the cross-border payment market. In contrast, each correspondent limits its service

\footnotetext{
5 Note that, in the end, these costs are passed on to the payer and/or payee depending on the charge code. The code OUR is used to denote that the payer covers all transaction fees, BEN indicates that the beneficiary bears all the costs, and SHA indicates that payer and payee share the costs.
} 
Fig. 2 Bilateral transactions

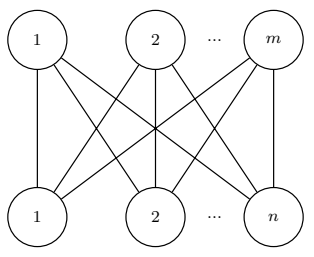

Fig. 3 Interbank intermediation

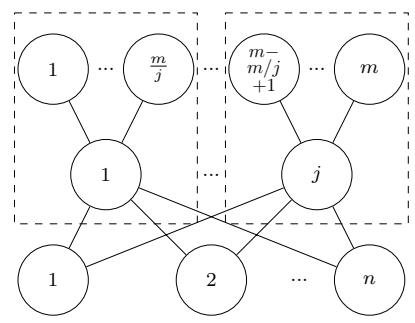

to a few foreign banks in a specific region, jurisdiction, or category of clients due to regulatory requirements and risk management considerations (Committee on Payments and Market Infrastructures 2016). ${ }^{6}$

To evaluate if the employment of correspondents and the resulting decrease in interbank transactions also reduces costs, further analysis is necessary. Therefore, it is important to consider the different types of transaction costs that arise for the banks when payments are processed.

In principle, transaction costs are classified according to their traceability (direct or indirect costs) and/or to their relationship with the transaction volume (variable or fixed costs)_compare Table 1. Each market participant faces market entry costs, $c_{1}$. These costs are volume independent (i.e., fixed) and cannot be attributed to a specific transaction. In case of cross-border payments, this could be, e.g., costs for a payment processor license. In addition, there are fixed costs that are directly attributable to the transaction, $c_{2}$. In the considered use case, these could be costs for establishing and managing counter-party bank relationships, directly with the correspondent or the foreign bank, respectively. There are also direct costs, $c_{3}$, which depend on the transferred money volume. Examples are foreign exchange costs or payment processing fees. With increasing payment orders, more processing fees accumulate. Finally, there are general costs that depend on the total volume, but are not attributable to a specific transaction, $c_{4}$. An example is the opportunity costs for trapped liquidity that banks are required to hold on their Nostro accounts to settle payments.

Every market participant is considered to have the same cost parameters and functions, i.e., is able to process the same amount of payments. This is done to rule out

\footnotetext{
${ }^{6}$ Theoretically, it is also possible to assume that each correspondent $j$ has a relationship with all foreign banks. This would result in $m * j+n * j$ transactions. Depending on the number of correspondents, i.e., if $j \leq \frac{m * n}{m+n}$, this system could have a lower number of transactions in comparison to the bilateral system. However, such a system is not only inferior to the one depicted in Fig. 3, but also at odds with reality.
} 
Table 1 Different types of transaction costs

Transaction volume

Transaction volume

Independent costs

Dependent costs

Costs not directly attributable to specific transactions $c_{1}$

Costs directly attributable to specific transactions

$c_{1}$

$c_{2}$

$c_{4}$

$c_{3}$

This table is adapted from Breuer (1993) and displays the different transaction costs. Transaction costs can either be fixed (volume independent) or variable. Moreover costs can be distinguished into direct and general, i.e., not clearly attributable costs

any biases stemming from specialized banks in the systems (i.e., more cost efficient banks). All market participants are banks and face similar regulatory costs (e.g., licensing fees or costs for know-your-customer checks etc.). In addition, all banks involved have volume-dependent costs for funding interbank accounts as well as processing and managing exposures (Casu and Wandhöfer 2018).

As a result, the costs for a domestic bank in a bilateral system amount to:

$$
c^{D}=c_{1}+m c_{2}+m c_{3}\left(\frac{V}{m n}\right)+c_{4}\left(\frac{V}{n}\right),
$$

where $V$ denotes the volume of all cross-border payments, $\frac{V}{m n}$ the volume for each transaction, and $\frac{V}{n}$ the volume per domestic bank. Respectively, the transaction costs for each foreign bank are given by:

$$
c^{F}=c_{1}+n c_{2}+n c_{3}\left(\frac{V}{m n}\right)+c_{4}\left(\frac{V}{m}\right),
$$

where $\frac{V}{m}$ denotes the payment volume per foreign bank. Consequently, in a bilateral system with $n$ domestic and $m$ foreign banks (compare Fig. 2), the transaction costs sum up to:

$$
\begin{array}{r}
c=n c^{D}+m c^{F} \\
c=[m+n] c_{1}+2 m n c_{2}+2 m n c_{3}\left(\frac{V}{m n}\right)
\end{array}
$$

$$
+n c_{4}\left(\frac{V}{n}\right)+m c_{4}\left(\frac{V}{m}\right) .
$$

In comparison, if $j$ correspondents are involved (compare Fig. 3), each domestic bank has transaction costs of:

$$
\hat{c}^{D}=c_{1}+j c_{2}+j c_{3}\left(\frac{V}{j n}\right)+c_{4}\left(\frac{V}{n}\right) .
$$

Instead of directly processing payments to foreign banks, the domestic banks forward payment instructions to the specific correspondents. In turn, the correspondent forwards the payment to the foreign bank. The costs for the foreign bank can be described by: 


$$
\hat{c}^{F}=c_{1}+c_{2}+c_{3}\left(\frac{V}{m}\right)+c_{4}\left(\frac{V}{m}\right) .
$$

In addition to the bilateral model, each correspondent bank also faces costs for their transmitting services:

$$
\begin{aligned}
\hat{c}^{B}=c_{1}+\left[n+\frac{m}{j}\right] c_{2} & \\
& +n c_{3}\left(\frac{V}{j n}\right)+\frac{m}{j} c_{3}\left(\frac{V}{m}\right)+c_{4}\left(\frac{V}{j}\right) .
\end{aligned}
$$

As a result, in a system with $j$ correspondents, $n$ domestic, and $m$ foreign banks, the overall transaction costs are given by:

$$
\begin{aligned}
\hat{c}=n \hat{c}^{D}+m \hat{c}^{F}+j \hat{c}^{B} & \\
\hat{c}=[m+n+j] c_{1}+2[j n+m] c_{2} & \\
& +2\left[j n c_{3}\left(\frac{V}{j n}\right)+m c_{3}\left(\frac{V}{m}\right)\right] \\
& +n c_{4}\left(\frac{V}{n}\right)+m c_{4}\left(\frac{V}{m}\right)+j c_{4}\left(\frac{V}{j}\right) .
\end{aligned}
$$

To assess potential benefits of a correspondent banking system, the economy-wide costs with and without interbank intermediaries must be compared. Subtracting Eq. (7) from Eq. (3) reveals the cost differences between the two systems:

$$
\begin{aligned}
c-\hat{c}= & -j c_{1}-j c_{4}\left(\frac{V}{j}\right)+2[m n-(j n+m)] c_{2} \\
& +2\left[m n c_{3}\left(\frac{V}{m n}\right)-\left[j n c_{3}\left(\frac{V}{j n}\right)+m c_{3}\left(\frac{V}{m}\right)\right]\right] .
\end{aligned}
$$

If the cost reduction in $c_{2}$ and $c_{3}$ through interbank intermediaries exceeds the additional costs $c_{1}$ and $c_{4}$, correspondents are beneficial. $c_{1}$ increases with the number of correspondents in the market. The general costs $c_{4}$ for processing payments increase with both volume and the number of involved correspondents, because more liquidity is trapped on the respective Nostro accounts. For a sufficiently small number of correspondents, i.e., $j \leq \frac{m(n-1)}{n}$, interbank intermediaries result in lower network costs, $c_{2}$. Instead of maintaining business relationships with all counter parties, the domestic and foreign banks only interact with their correspondents. The network costs decrease as the number of domestic and foreign banks per correspondent increases. If the cost function $c_{3}$ is increasing at a decreasing rate, then correspondents can result in lower foreign exchange and payment processing fees. In other words, in this case, correspondents have economies of scale. An example for such a cost function is $c_{3}(V)=a V^{c}$, where $a>0$ and $0<c<1$. For this cost function, a lower $c_{3}$ is attained if there is a sufficient amount of foreign and domestic banks relative to the number of correspondents in the market. The sufficient amount is defined 
as $\min \{m, n\} \geq\left[1+j^{1-c}\right]^{\frac{1}{1-c}}$. If the number of correspondents $(j)$ and the economies of scale parameter $(c)$ are constant, then the cost saving increases with a higher number of foreign and domestic banks. Newman et al. (2018) cite processing payments $\left(c_{3}\right)$ as the most significant cost in cross-border transactions. Although cited as important, opportunity costs for trapped liquidity $\left(c_{4}\right)$ were found to be less significant than processing payment costs. The effect of the network management costs $\left(c_{2}\right)$ was found to be low and that of market entry costs $\left(c_{1}\right)$ is cited as negligible. In the case of a relatively high number of foreign and domestic banks compared to correspondents in the market, the positive effect of $c_{2}$ and $c_{3}$ outweighs the additional costs of $c_{1}$ and $c_{4}$. Since the correspondent banking market is best described by an oligopoly, i.e., the cross-border payment services are controlled by a few large correspondents, this holds true. Consequently, correspondents reduce the overall costs.

\section{The downfall of interbank intermediaries}

\subsection{The digital transformation of correspondent banking}

\subsubsection{Distributed ledger technology}

The previously described correspondent banking system was developed when communication was still costly, slow, and unreliable. Banks faced regulatory, as well as technical differences in national payment systems. As a result, there is limited transparency regarding the status of payments in this system. Depending on the parties involved, different requirements need to be met, e.g., some national payment systems (e.g., Fedwire and CHIPS in the U.S., or the Australian, Swiss, and Japanese RTGS systems) do not use SWIFT messages (Casu and Wandhöfer 2018). The correspondent banking system is susceptible to payment delays as not all involved banks hold enough liquidity in the correct currency. As a result of the internet and the accompanied digitization, expectations by consumers for transparency, speed, and reduced transaction costs have risen. In a world where online shopping enables real-time tracking and free delivery of physical goods within a few hours, customers struggle to accept opaque cross-border payments that take several days. Despite significant investments by SWIFT and other banks, the cross-border payment infrastructure remains suboptimal. From a financial stability perspective, the correspondent banking system is also a source of risk (Freixas and Parigi 1998; Allen et al. 2012; Del Prete and Federico 2019). Although, for simplification, banks use

\footnotetext{
7 Note that the derived relation would be most beneficial for a monopolistic correspondent that could evolve from the suggested cost function. As the cross-border market is clearly not controlled by a unique correspondent, the proposed cost function should be interpreted as a piecewise-defined function of an overall cubic cost function. Costs first increase at a decreasing rate (as advocated) and then increase at increasing rates after an optimal number and volume of processed payments are reached by a correspondent. If a cubic cost function is assumed, the existing oligopoly market structure can be rationalized.
} 


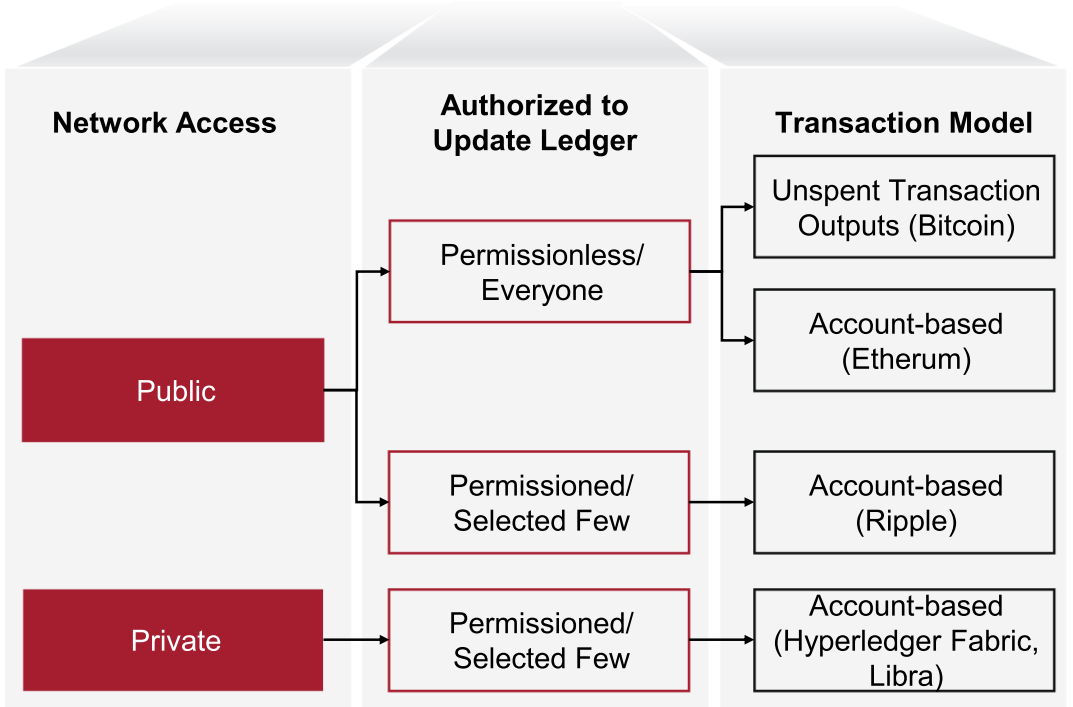

Fig. 4 Distributed ledger taxonomy

interbank credit lines to fulfill payment transactions for their customers, this is a potential contagion source in periods of financial stress (Afonso and Shin 2011).

To address these issues, recently, banks have begun to explore modern technological options (Thakor 2020). Here, specifically, the potential of DLT to revolutionize long-distance transactions is examined. Technically speaking, DLT allows for a consensus record of state changes or updates to a synchronized ledger to be distributed across various nodes in the network. Important to note is that DLT is not a single well-defined technology, and that nomenclature is not standardized within literature (Perdana et al. 2020). To make the topic more clear and to show the terms used here, Fig. 4 shows an overview. In general, it is differentiated between public (anyone can join) and private (members can join based on credentials) DLT systems (see Fig. 4). In all cases, the crucial aspect of DLT, however, is that unlike the correspondent banking system where each financial institution in the payment chain updates its individual databases (i.e., the Nostro and Loro accounts), in a DLT system, a central ledger is shared, replicated, and synchronized among the members of a decentralized network (Natarajan et al. 2017).

DLT systems are differentiated based on who is included in the group that updates the ledger. In the case of permissionless systems, all members can update the ledger. In permissioned setups, only certain members can update the ledger. The group governs and agrees by consensus on database updates, i.e., new transaction records. Thereby, the consensus is reached via a predefined cryptographic validation method, i.e., a set of rules. Such a consensus mechanism is necessary to establish whether a particular transaction is legitimate or not, and to ensure a correct sequencing of transactions done with the same assets. Every record has a timestamp and a 
unique cryptographic signature, making the ledger a verifiable, immutable history of all transactions in the network. ${ }^{8}$

Two different record-keeping models are commonly used in DLT systems, UTXO (unspent transaction output, sometimes referred to as store of value) and accountbased (Kahn and Roberds 2009; Kahn et al. 2019). For a transaction to be deemed satisfactory in an account-based system, the payer has to be identified as the holder of the account from which the payment is made. The account balance of the payer is checked to ensure that the transaction amount is covered. The account value of the payer is then reduced and the money is added to the account of the payee. In the case of a UTXO-based system, information about the amount available from the payer for the transaction is stored in the unspent transaction output. This total value is used as the input for the transaction. In a second step, a new UTXO (total amount minus transaction amount) is sent back to a newly created address of the payer and the transaction amount is stored in a new output of the payee. The UTXO model is often compared to a cash system. During a transaction, to cover the cost, several bills can be used (existing outputs), and in some cases, change is returned (new output). In total, each bill can only be used once (the original output no longer exists after the transaction). ${ }^{9}$

\subsubsection{RippleNet: a new global-payment system}

Recently, several banks, e.g., Royal Bank of Canada, Santander, UBS, etc., have begun to use a public permissioned account-based DLT system to transfer payments across borders. The banks use the closed-source banking software RippleNet that is sold by Ripple Labs, Inc. and is different from Ripple's own currency XRP (colloquially also referred to as Ripple). Access to this system is naturally permissioned, i.e., participating banks are pre-selected by an administrator, i.e., Ripple Labs, who controls network access and sets the rules of the database. RippleNet is a distributed database that contains information about user accounts, balances, and trades (Ripple 2017). A trade or payment is executed by making a valid change to the central ledger. Here, an interledger protocol connects the different payment record systems of all participating banks from which it creates the central ledger. The central ledger is shared and maintained by all network members and represents every user's balance. Currencies enter and exit the Ripple network via gateways, i.e., banks (Rapoport et al. 2014). Analogously to traditional banks, these gateways accept currency deposits from customers and issue balances on the Ripple network. When a user wants to withdraw money from the Ripple network, the existing balance is redeemed. For security purposes, every user of RippleNet must hold a small amount of XRP. Within the network, payments can either be processed directly via XRP debit payments or indirectly via path-based currency-agnostic "I owe you" (IOU) settlement transactions

\footnotetext{
${ }^{8}$ Note that many of the technical constructs are simplified here. For a more detailed and technical description, the reader is referred to Natarajan et al. (2017).

9 For more details on the UTXO model, see, e.g., Sun (2018).
} 


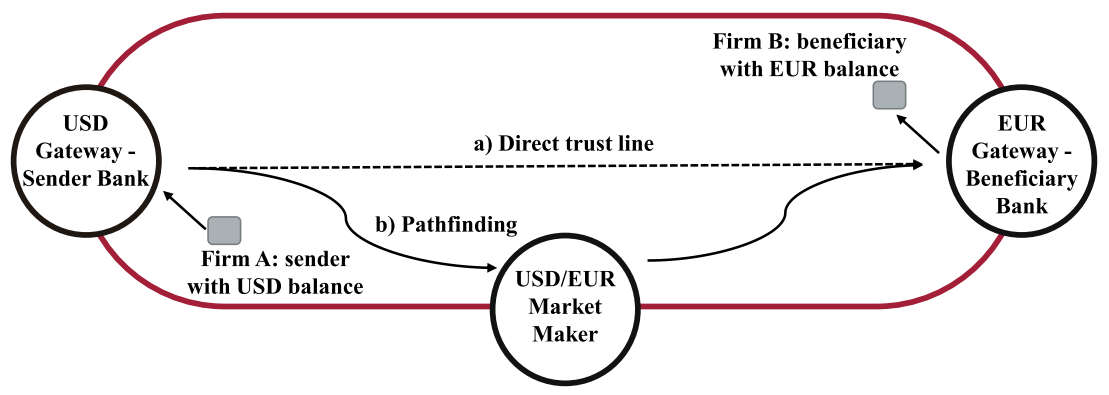

Fig. 5 Cross-border payments via RippleNet

(Moreno-Sanchez and Zafar 2016). In the case of IOU settlement transactions, banks can use fiat currencies (USD, Euro, etc.) to settle cross-border payments without any conversion to cryptocurrency. In this case, XRP is only used to pay the minute transaction fee imposed to prevent senseless transactions (Rapoport et al. 2014). To settle credit between sender and receiver, the most suitable route of credit between the sender's and receiver's banks is used (Moreno-Sanchez et al. 2018). Whenever a payment is made that involves two banks that are not connected by a direct trust line (i.e., Nostro accounts), the payment "ripples" through other trust relationships in the network. These trust relationships are banks that hold the specific currency pairs and function as market makers. By routing a payment through one (or several) market maker(s), banks can pay each other in currencies that they do not hold (or do not want to hold). The system automatically uses the most competitive exchange rates, i.e., the cheapest path. The money is simultaneously debited from the payer's account and credited to the beneficiary. For example, an American company A would like to transfer money to a European firm B. After checking for liquidity and verifying the client's identification (legally required), the bank of the sender can simply send an IOU in USD to the beneficiary's European bank (compare Fig. 5). At the same time, the beneficiary's bank must also put the transaction amount on hold. This step is necessary to accommodate the desire of the beneficiary to receive the money in Euros despite the transfer of USD. Once both banks have validated that the funds are on hold, the funds are released. A market maker becomes necessary if the beneficiary bank in Europe does not want to hold USD (compare Fig. 5). The market maker holds trust lines with the sender and the beneficiary bank and is paid a small fee (bid-ask spread) for the foreign exchange. ${ }^{10}$

RippleNet simplifies cross-border transactions enabling on-demand liquidity across multiple currencies for banks. It is capable of processing 1500 transactions per seconds and a typical payment only takes about 4-5 s between initiation and

\footnotetext{
${ }^{10}$ For very exotic currencies, XRP can be used as a vehicle currency. Most banks, however, opt not to use XRP (Pick 2020). Therefore, a detailed discussion of this feature is omitted here. For more information on XRP settlement, see e.g., Ripple (2017).
} 
completion (Travis 2017). RippleNet integrates well into an already existing and highly regulated payment system. "In other words, while Ripple[Net] improves the underlying settlement infrastructure of global-payment systems, it does not affect the existing legal relationships between the participants of such systems" (Rosner and Kang 2016, p. 664). Banks must still continue to comply with financial regulations, anti-money laundering, and know-your-customer rules. RippleNet also lowers some of the risks that current regulations seek to mitigate. For instance, the adoption of atomic (all or nothing) real-time settlement drastically reduces the risk of lost payments.

While from a technological perspective, RippleNet and other DLT systems are generally considered to offer secure, immutable, and transparent transactions, legal liability will simply not disappear (Zetzsche et al. 2018). Risks that are particularly pronounced due to the early level of RippleNet implementation are the lack of liquidity and the poor inter-connectivity of certain banks. Moreno-Sanchez et al. (2018) show that if banks are poorly interconnected, then it is possible that users can no longer access their funds even if the involved sender and beneficiary bank are not insolvent. In this case, the issue of liability is unclear. The same holds true for the case of unintended third-party access (cyberattack) or the "garbage in, garbage out" dilemma, i.e., the spread of inaccurate stored data via DLT. In case of RippleNet, Ripple Labs controls the rules (Armknecht et al. 2015) and access to the database (Ripple 2017). ${ }^{11}$ This allows the entities involved to be known. In turn, the particular entity could be directly liable for economic losses in the case of its breach. Nonetheless, the fundamental joint control of DLT will likely result in a joint liability of the network participants, including Ripple Labs (Zetzsche et al. 2018).

Due to the inherently international nature of RippleNet's activities, both domestic and international laws must be considered. For example, regulators have concerns about the monopoly position of RippleNet in cross-border payments (European Securities and Markets Authority 2017). In addition, regulators must decide under which jurisdictions conflicts fall, e.g., which insolvency law to follow in the case of a bank's default (Rosner and Kang 2016). Therefore, regulators must coordinate and communicate to harmonize global standards and rules. Although the use of XRP could simplify issues due to international regulations, most banks do not yet use it as a vehicle currency. The digital currency is only worth what someone else is willing to pay for it. Ripple Labs owns about $60 \%$ of all XRP and controls the money supply in the network (Pick 2020). Users are forced to trust Ripple Labs with the fate of their money.

Overall, for a successful wide-spread implementation, it is vital that all network elements receive sufficient supervision. For securing trust in the new payment infrastructure, more research on the resiliency and weakness of the system is needed.

\footnotetext{
11 As fairly mentioned by Rosner and Kang (2016), in principle, no single entity can change the RippleNet database. However, most of the validating servers are run by Ripple Labs, allowing it to change the database.
} 


\subsection{Implications for the correspondent banking system}

In the following, the transaction cost model of Breuer (1993) is used to illustrate how DLT systems, like RippleNet, affect the correspondent banking system. Instead of relying on several specialized correspondents, domestic and foreign banks use a shared network that is based on a permissioned DLT and transfer funds directly (compare Fig. 6).

In case of cross-border payments via DLT, the costs for a domestic and a foreign bank reduce to:

$$
\begin{aligned}
& \bar{c}^{D}=c_{1}+c_{2}+c_{3}\left(\frac{V}{n}\right)+c_{4}\left(\frac{V}{n}\right) . \\
& \bar{c}^{F}=c_{1}+c_{2}+c_{3}\left(\frac{V}{m}\right)+c_{4}\left(\frac{V}{m}\right) .
\end{aligned}
$$

Instead of maintaining $j$ counter-party relationships, each bank only maintains access to the Ripple network. This reduces the network costs for each bank to $c_{2}$. Similarly, due to the fact that less parties are involved, the processing fees $c_{3}$ can be reduced, too. Instead of processing messages to $j$ correspondents and keeping internal records to capture proprietary aspects of each currency transfer, both banks only face one-time costs, consisting out of the direct transfer costs and costs for validating transactions on the ledger. Like in the correspondent banking system, banks still have to provide sufficient funds in their account to process the payments.

Even though a lot of interbank intermediaries can be excluded in this system, at least one administrator $(A)$ for the market place is needed. The administrator faces market entry costs $\tau_{1}$ to set up the system. Additionally, the administrator has to verify all domestic and foreign banks (resulting in costs $\tau_{2}$ ), ensuring that they have the ability to process payments. Once the information is digital, it can be easily verified and shared among all network members. Making use of the distributed exchange capability, cross-border payments are automatically processed among network members, resulting in $\tau_{3}$. The instant real-time settlement of transactions basically eliminates the time and cost of capital $\left(\tau_{4}\right)$ that is locked during a cross-border transfer. Still, the administrator faces $\tau_{4}$ costs for the infrastructure, i.e., capacity costs that incur to be able to process all payments. Thus, the costs for the administrator can be described by:

Fig. 6 Intermediation via DLT

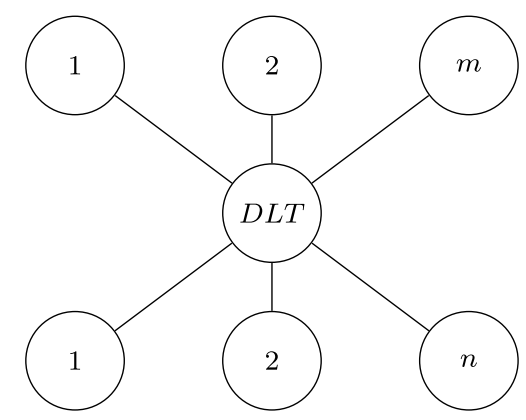




$$
\begin{aligned}
\bar{c}^{A}=\tau_{1}+(m+n) \tau_{2} & \\
& +n \tau_{3}\left(\frac{V}{n}\right)+m \tau_{3}\left(\frac{V}{m}\right)+\tau_{4}(V) .
\end{aligned}
$$

As a result, in a DLT system, the following transaction costs incur:

$$
\begin{aligned}
\bar{c}=n \bar{c}^{D}+m \bar{c}^{F}+\bar{c}^{A} & \\
\bar{c}=(m+n) c_{1}+\tau_{1}+(m+n)\left(c_{2}+\tau_{2}\right) & \\
& +n\left[c_{3}\left(\frac{V}{n}\right)+\tau_{3}\left(\frac{V}{n}\right)\right] \\
& +m\left[c_{3}\left(\frac{V}{m}\right)+\tau_{3}\left(\frac{V}{m}\right)\right] \\
& +n c_{4}\left(\frac{V}{n}\right)+m c_{4}\left(\frac{V}{m}\right)+\tau_{4}(V) .
\end{aligned}
$$

To assess potential benefits of the DLT system, the economy-wide costs of the DLT system must be compared to those of the correspondent banking system. Subtracting Eq. (12) from Eq. (7) reveals the economy-wide differences between the two systems:

$$
\begin{aligned}
\hat{c}-\bar{c}=j c_{1}-\tau_{1}+j c_{4}\left(\frac{V}{j}\right)-\tau_{4}(V) & \\
+ & {[2 j n+m-n] c_{2}-(n+m) \tau_{2} } \\
& +2 j n c_{3}\left(\frac{V}{j n}\right)-n\left[c_{3}\left(\frac{V}{n}\right)+\tau_{3}\left(\frac{V}{n}\right)\right] \\
& +m\left[c_{3}\left(\frac{V}{m}\right)-\tau_{3}\left(\frac{V}{m}\right)\right] .
\end{aligned}
$$

Although the initial infrastructure required for a DLT platform is far more costly $\left(\tau_{1}\right)$ than a simple banking license $\left(c_{1}\right)$, in relative terms considering the sheer number of existing correspondents $j$, the technology is remunerative. While there are little data on the costs of public permissioned DLT systems, Brody et al. (2019) estimate an initial investment equivalent to approximately 26 German banking licenses, i.e., correspondent banks. ${ }^{12}$ Currently, there are about 361 correspondent banks in the Euro business alone. For a sufficiently large number of correspondents $(\sim 26)$, the DLT system results in lower market entry costs. A DLT system reduces networking costs if onboarding $\left(\tau_{2}\right)$ is less expensive than it is for banks to establish counterparty relationships $\left(c_{2}\right)$. There is limited information on both the onboarding costs in a DLT system and the banks' network costs. It seems plausible, however, that both the administrator and correspondents have economies of scale in establishing additional relationships (Maringer et al. 2019). While an administrator must accumulate

\footnotetext{
12 According to Haag and Steffen (2020), the German Federal Financial Supervisory Authority BaFin charges a fee of up to $\$ 25,000$ for granting a banking license.
} 
knowledge about the regulatory environment and how to establish trustworthy relationships, correspondents potentially already possess unique proprietary knowledge. The exact relation between $\tau_{2}$ and $c_{2}$ is hard to determine. Although $c_{2}$ may possibly be lower than $\tau_{2}$, with an increasing number of correspondents, the DLT system can result in lower network costs. Anecdotal evidence indicates that it is simply too costly for correspondents to establish and maintain banking relationship for certain geographic regions (Bräuning and Fecht 2017; Kobayashi and Takaguchi 2018). The number of correspondents has been steadily decreasing over the last years and the remaining correspondents have even pared back their relationships. This resulted in even higher cross-border payments costs in abandoned regions (Rice et al. 2020). In contrast, technologies such as RippleNet enable banks to exchange funds without dedicated pre-established networks for the target location of the transaction as long as both institutions are connected via the system.

Payment processing costs can be significantly reduced in the DLT system, because failures of payments are minimized through the automatic real-time settlement (Ripple 2017). In the current correspondent system, complex interbank pricing rules create the need for manual invoicing, claims-handling, and dispute management. This requires substantial manpower and valuable time for transaction execution. In addition, due to the presence of market makers, an universal intermediate currency (e.g., XRP) and cost beneficial path settlements, foreign exchange costs can be reduced. Currently, managing cash reserves in multiple currencies makes optimizing payment flows challenging. The DLT system will reduce operational costs linked to the processing of payments, i.e., $\tau_{3}(\cdot)<c_{3}(\cdot)$ holds true. The main challenge for the administrator, e.g., Ripple Labs, is to ensure that the processing power to support an increasing number of transactions per second is available, i.e., the system is scalable. The required computing is energy intensive (Leopold and Englesson 2017; Truby 2018). Brody et al. (2019) cite ongoing maintenance $\left(\tau_{4}\right)$ as the most significant running cost for a public permissioned DLT system. In the case of correspondents, typically, opportunity costs for trapped liquidity $\left(c_{4}\right)$ are a major cost factor. Nonetheless, given the required processing power and energy, maintaining a DLT system might still be more expensive. However, in case of a relatively high number of correspondents, the positive effect of $\tau_{1}, \tau_{2}$, and $\tau_{3}$ outweighs the additional costs of $\tau_{4}$. Consequently, in principle, a DLT system results in an overall cost saving. The magnitude of improvement greatly depends on network effects that can only be created by on-board large banks around the world (Iansiti and Lakhani 2017). To achieve this, building and maintaining trust in the new payment system are vital.

\section{Conclusion}

Traditional correspondent banking networks are still prevalent for cross-border payments. Here, transaction cost theory was used to show the amenities of such interbank intermediaries. Subsequently, the effect of a DLT-based system on the cross-border payment market was analyzed. DLT has the potential to replace correspondents and dominate cross-border payments by reducing the overall transaction 
costs. DLT is a nascent technology that could form the basis of a new cross-border commercial payments network. The speed of acceptance by banks around the world and the rate at which legal concerns are addressed will determine when DLT can be used to support trillions of dollars in payments.

Acknowledgements I thank Max Bruche, Werner Neus, Anna Staerz, Sebastian Weitz, the audience at the World Finance Conference 2020, and two anonymous reviewers for their helpful suggestions and comments.

Funding Open Access funding enabled and organized by Projekt DEAL.

Open Access This article is licensed under a Creative Commons Attribution 4.0 International License, which permits use, sharing, adaptation, distribution and reproduction in any medium or format, as long as you give appropriate credit to the original author(s) and the source, provide a link to the Creative Commons licence, and indicate if changes were made. The images or other third party material in this article are included in the article's Creative Commons licence, unless indicated otherwise in a credit line to the material. If material is not included in the article's Creative Commons licence and your intended use is not permitted by statutory regulation or exceeds the permitted use, you will need to obtain permission directly from the copyright holder. To view a copy of this licence, visit http://creativecommons.org/licen ses/by/4.0/.

\section{References}

Afonso, G., \& Shin, H. S. (2011). Precautionary demand and liquidity in payment systems. Journal of Money, Credit and Banking,43, 589-619. https://doi.org/10.1111/j.1538-4616.2011.00454.x.

Allen, F., Babus, A., \& Carletti, E. (2012). Asset commonality, debt maturity and systemic risk. Journal of Financial Economics,104(3), 519-534. https://doi.org/10.1016/j.jfineco.2011.07.003.

Armknecht, F., Karame, G.O., Mandal, A., Youssef, F., \& Zenner, E. (2015). Ripple: Overview and outlook. In: Conti, M., Schunter, M., \& Askoxylakis, I. (eds). International Conference on Trust and Trustworthy Computing, Springer International Publishing, pp. 163-180.

Auer, R., \& Boehme, R. (2020). The technology of retail central bank digital currency. Quarterly Review, March: 85-100, Bank for International Settlements.

Bank of Canada, Bank of England, and Monetary Authority of Singapore (2018) Cross-border interbank payments and settlements. Emerging opportunities for digital transformation, https://www.mas.gov. sg/-/media/MAS/ProjectUbin/Cross-Border-Interbank-Payments-and-Settlements.pdf.

Boar, C., Holden, H., \& Wadsworth, A. (2020). Impending arrival-a sequel to the survey on central bank digital currency. Paper 107, Bank for International Settlements

Böhme, R., Christin, N., Edelman, B., \& Moore, T. (2015). Bitcoin: Economics, technology, and governance. Journal of Economic Perspectives, 29(2), 213-38.

Boot, A., Hoffmann, P., Laeven, L., \& Ratnovski, L. (2021). Fintech: whats old, whats new? Journal of Financial Stability,53, 100836.

Bräuning, F., \& Fecht, F. (2017). Relationship lending in the interbank market and the price of liquidity. Review of Finance,21(1), 33-75. https://doi.org/10.1093/rof/rfw042.

Breuer, W. (1993). Finanzintermediation im Kapitalmarktgleichgewicht. Berlin: Springer-Verlag.

Brody, P., Holmes, A., Wolfsohn, E., \& Frechette, J. (2019). Total cost of ownerhship for blockchain solutions. Tech. rep., Ernst \& Young LLP. https://www.ey.com/Publication/vwLUAssets/ey-total -cost-of-ownership-for-blockchain-solutions/\$File/ey-total-cost-of-ownership-for-blockchain-solut ions.pdf.

Bruno, P., Denecker, O., \& Niederkorn, M. (2019). Global payments report 2019: Amidst sustained growth, accelerating challenges demand bold actions. September, McKinsey: Global Banking Practice. 
Calomiris, C. W., \& Carlson, M. (2017). Interbank networks in the national banking era: Their purpose and their role in the panic of 1893. Journal of Financial Economics,125(3), 434-453. https://doi. org/10.1016/j.jfineco.2017.06.007.

Casu, B., \& Wandhöfer, R. (2018). The future of correspondent banking cross border payments. Institute working paper no. 2017-001, Society for Worldwide Interbank Financial Telecommunication.

Committee on Payments and Market Infrastructures. (2016). Correspondent banking. Working Paper, July, Bank for International Settlement.

Committee on Payments and Market Infrastructures. (2018). Cross-border retail payments. Working Paper, February, Bank for International Settlement.

Committee on Payments and Market Infrastructures. (2019). Correspondent banking data. Tech. rep., Bank for International Settlement Market Analysis. https://www.bis.org/cpmi/paysysinfo/corr_ bank_data/data_1905.xlsx.

Craig, B., \& von Peter, G. (2014). Interbank tiering and money center banks. Journal of Financial Intermediation,23(3), 322-347. https://doi.org/10.1016/j.jfi.2014.02.003.

Del Prete, S., \& Federico, S. (2019). Does trust among banks matter for bilateral trade? Evidence from shocks in the interbank market. https://www.bancaditalia.it/pubblicazioni/temi-discussion e/2019/2019-1217/en_Tema_1217.pdf.

Denecker, O., Istace, F., Masanam, P. K., \& Niederkorn, M. (2016). Rethinking correspondent banking. McKinsey on Payments 23, McKinsey

Diamond, D. W. (1984). Financial intermediation and delegated monitoring. The Review of Economic Studies,51(3), 393-414. https://doi.org/10.2307/22974300.

Diamond, D. W., \& Dybvig, P. H. (1983). Bank runs, deposit insurance, and liquidity. Journal of Political Economy,91(3), 401-419. https://doi.org/10.1086/2611551.

European Central Bank. (2016). Tenth survey on correspondent banking in euro. https://doi.org/10.111 1/j.1538-4616.2011.00454.x2.

European Securities and Markets Authority. (2017). The distributed ledger technology applied to securities markets, https://doi.org/10.1111/j.1538-4616.2011.00454.x3.

Freixas, X., \& Parigi, B. (1998). Contagion and efficiency in gross and net interbank payment systems. Journal of Financial Intermediation, 7(1), 3-31. https://doi.org/10.1006/jfin.1998.02304.

Grant, J. C. (1986). Electronic banking and telecommunications. Information and Management,11(1), 3-7. https://doi.org/10.1016/0378-7206(86)90070-45.

Haag, H., \& Steffen, J. L. (2020). Banking regulation in Germany: Overview. Tech. rep., Hengeler Mueller, https://doi.org/10.1111/j.1538-4616.2011.00454.x6.

He, D., Leckow, R.B., Haksar, V., Mancini-Griffoli, T., Jenkinson, N., Kashima, M., Khiaonarong, T., Rochon, C., \& Tourpe, H. (2017). Fintech and financial services: Initial considerations. Staff Discussion Note 17/05, International Monetary Fund.

Hüser, A.C. (2016). Too interconnected to fail: A survey of the interbank networks literature. Safe working paper no. 91, Goethe University Frankfurt.

Iansiti, M., \& Lakhani, K. R. (2017). The truth about blockchain. Harvard Business Review95(1), $118-127$.

Kahn, C. M., \& Roberds, W. (2009). Why pay? An introduction to payments economics. Journal of Financial Intermediation,18(1), 1-23. https://doi.org/10.1016/j.jfi.2008.09.0017.

Kahn, C. M, Rivadeneyra, F., Wong, T. N. (2019). Should the central bank issue e-money? Working Paper 2019-003a, Federal Reserve Bank of St. Louis.

Kobayashi, T., \& Takaguchi, T. (2018). Identifying relationship lending in the interbank market: A network approach. Journal of Banking and Finance,97, 20-36. https://doi.org/10.1016/j.jbank fin.2018.09.0188.

Kohn, M. (1999) Early deposit banking. Working paper 99-3, Dartmouth College.

Koning, J. (2016). Fedcoin: A central bank issued cryptocurrency. R3 Reports, November, R3.

Leopold, S.J., \& Englesson, L. (2017). How eco friendly is our money and is there an alternative? https:// doi.org/10.1016/j.jfineco.2011.07.0039.

Maringer, D.G., Craig, B.R., \& Paterlini, S. (2019). Recreating banking networks under decreasing fixed costs. Tech. rep., Federal Reserve Bank of Cleveland Working Paper 19-21.

Mills, D. C., Wang, K., Malone, B., Ravi, A., Marquardt, J.C, Chen, C., Badev, A., Brezinski, T., Fahy, L., Liao, K., Kargenian, V., Ellithorpe, M., Ng, W., \& Baird, M. (2016). Distributed ledger technology in payments, clearing, and settlement. Finance and Economics Discussion Series 2016-095, Washington: Board of Governors of the Federal Reserve System. 
Moreno-Sanchez, P., \& Zafar, M. B. (2016). Listening to whispers of Ripple: Linking wallets and deanonymizing transactions in the Ripple network. Proceedings on Privacy Enhancing Technologies,4, 436-453. https://doi.org/10.1515/popets-2016-00490.

Moreno-Sanchez, P., Modi, N., Songhela, R., Kate, A., \& Fahmy, S. (2018). Mind your credit: Assessing the health of the Ripple credit network. In: Proceedings of the 2018 World Wide Web Conference, pp 329-338. https://doi.org/10.1145/3178876.3186099.

Narayanan, A., Bonneau, J., Felten, E., Miller, A., \& Goldfeder, S. (2016). Bitcoin and cryptocurrency technologies: A comprehensive introduction. Princeton University Press.

Natarajan, H., Krause, S., Gradstein, H. (2017). Distributed ledger technology and blockchain. FinTech Note, No. 1, World Bank.

Newman, H., Denecker, O., Digiacomo, N., Meurant, L., Höll, R., Raymaekers, W., et al. (2018). A vision for the future of cross-border payments. October, SWIFT and McKinsey: Global Banking Practice.

Perdana, A., Robb, A., Balachandran, V., \& Rohde, F. (2020). Distributed ledger technology: Its evolutionary path and the road ahead. Information and Management p 103316. https://doi.org/10.1016/j. im.2020.103316.

Pick, C. (2020). XRP core report. https://doi.org/10.1016/j.jfineco.2011.07.0031.

Quinn, S. (1997). Goldsmith-banking: Mutual acceptance and interbanker clearing in restoration London. Explorations in Economic History,34(4), 411-432. https://doi.org/10.1006/exeh.1997.06822.

Quinn, S., \& Roberds, W. (2008). The evolution of the check as a means of payment: A historical survey. Vol. 93, Federal Reserve Bank of Atlanta.

Rapoport, P., Griffin, P., Leal, R., \& Sculley, W. (2014). The Ripple protocol: A deep dive for finance professionals. https://doi.org/10.1016/j.jfineco.2011.07.0033.

Raskin, M., \& Yermack, D. (2018). Digital currencies, decentralized ledgers and the future of central banking. In R. M. Lastra (Ed.), Conti-Brown P (pp. 474-486). Edward Elgar Publishing: Research Handbook on Central Banking.

Rice, T., von Peter, G., \& Boar, C. (2020). On the global retreat of correspondent banks. Quarterly Review, March: 37-52, Bank for International Settlements

Ripple. (2017). Ripple solution overview. https://doi.org/10.1016/j.jfineco.2011.07.0034.

Rosner, M. T., \& Kang, A. (2016). Understanding and regulating twenty-first century payment systems: The Ripple case study. Michigan Law Review,114(4), 649. https://heinonline.org/HOL/P?h=hein. journals/mlr114\&i=687

Rysman, M., \& Schuh, S. (2017). New innovations in payments. Innovation Policy and the Economy,17(1), 27-48. https://doi.org/10.1086/6888435.

Society for Worldwide Interbank Financial Telecommunication (2016) SWIFT: The global financial messaging provider. https://doi.org/10.1016/j.jfineco.2011.07.0036.

Sun, F. (2018). UTXO vs account/balance model. https://doi.org/10.1016/j.jfineco.2011.07.0037.

Swan, M. (2015) Blockchain: Blueprint for a new economy. O'Reilly Media, Inc.

Thakor, A. V. (2020). Fintech and banking: What do we know? Journal of Financial Intermediation,41, 100833. https://doi.org/10.1016/j.jfineco.2011.07.0038.

Travis, M. (2017) Ripple. The most (demonstrably) scalable blockchain. https://doi.org/10.1016/j.jfine co.2011.07.0039.

Truby, J. (2018). Decarbonizing bitcoin: Law and policy choices for reducing the energy consumption of blockchain technologies and digital currencies. Energy Research and Social Science,44, 399-410. https://www.mas.gov.sg/-/media/MAS/ProjectUbin/Cross-Border-Interbank-Payments-and-Settl ements.pdf0.

Vives, X. (2019). Digital disruption in banking. Annual Review of Financial Economics, 11, 243-272.

Zetzsche, D. A., Buckley, R. P., \& Arner, D. W. (2018) The distributed liability of distributed ledgers: Legal risks of blockchain. University of Illinois Law Review, pp. 1361-1406.

Publisher's Note Springer Nature remains neutral with regard to jurisdictional claims in published maps and institutional affiliations. 